\title{
The Analysis of University Teaching Chain Tallying with
}

\section{Country Practice}

\author{
Ying Liu \\ Associate professor, College of Business Management, Shenyang University \\ Shenyang 110036, Liaoning, China \\ E-mail: liuying234521@163.com
}

\begin{abstract}
During the process of university development, many people's understanding to university teaching and country practice chain only stayed in their own function field, and they didn't establish real humanism thoughts and even didn't recognize the heritage and correction function so that it caused the disjoint between university teaching and country practice and can't reach the prospective effect of university teaching plan. This paper based on the effecting factors of university teaching chain, country practice and tally defining and analyzing of the effecting factors of university teaching and country practice chain, and probes into the relationship between university teaching chains tallying with country practice, forms the model of university teaching tallying with country practice.
\end{abstract}

Keywords: University teaching chain, Country practice, Tally with

\section{Foreword}

During the process of university development, many people's understanding to university teaching and country practice chain only stayed in their own function field, and they didn't establish the combination thoughts of teaching and practice and even didn't recognize the heritage and correction function so that it caused the disjoint between university teaching and country practice and can't reach the prospective effect of university teaching plan. Under such background, it must attach importance to tallying with university teaching and country practice chain, improve the level of tallying with based on the understanding of teaching factors and specialty of country practice, thus make the undergraduate to know vast country and participate in practice in more extent.

Through summarize and appraise to literature of relative to country practice chain, it learn about the existence of contents need to be further studied and improved in this field. There is no co relational research for university teaching and country practice, this paper make the define and analysis for influence factors of teaching and practice, discuss the relevance variable for this kind of combination and the author consider that this relevance variable is the key factors to have the impact on combination.

\section{The definite of combination}

Different scholar has different answer to "combination" study; Nadler's presentation is about the consistency level with one factor's target, structure to another; Porter stated the strategic essence; and Kristof set forth the compatibility of teaching and practice as well as its premise and result. There are two type of combination: assistance and supplement. The assistance type is about the essential feature consistency between undergraduate's personality, values, goal, positive status etc and these features in country; supplement type means that the country practice replenish student's psychological need and their developing needs, or to say that undergraduate's personality, value, specialty, status and skill replenish country's needs. This "combination" breaks through the notion of teaching and practice; take the interaction viewing angle to study issues between university and country.

To classify of combination to teaching and practice roughly depends on three standards: (1) tallying with values, culture and atmosphere. This type of combination stresses the consistency of teaching and values of village official at present; the consistency of individual value perceive and individual expectation; the undergraduates define and evaluate the consistency to country value of their own side. (2) Take the target consistency for both teaching and country improving as combination standard, the more consistency the teaching and country overall objective have, the more combination will be. The more level of their improving objective, the more contributed for university to realize expectation objective, and undergraduates also can realize their personal goal via practice activity in country. (3) Take the relationship of demand and supply between teaching and practice as 
being standard for combination. Country provides the practice link to exchange improving work ability for student, whereas university provide all kinds of condition and surroundings to train learning ability to student. While the more fitting for each other, the more level of combination will have. This paper takes the investigation to the first standard.

The combination concept is divided into internal fit and external fit. Internal fit refers to the complementary and support among various teaching exercise such as teaching syllabus, teaching program me, curriculum setting, grade assessment, testing and cohere with students. External fit means the harmony between university management activity and country characteristics, i.e. the consistency of value for undergraduates, village officials and teachers; the consistency of values actual perception and individual expectations; students define and appraise the values similarities to country at their own side. Therefore, while studying the university teaching management, it must reach the matching level by insisting to get through internal consistent teaching management or teaching system (Internal fit), then obtain vertical fit by consistency of teaching system and optional practice link (external fit). In short, the key concerned point of this paper is about external combination viewpoint for teaching link and country time link.

\section{Combination process}

Combination process builds the passage way for teaching link and country practice link to integrate dynamically. "Combination" is the process in which the undergraduate must experience self-efficiency, hope, optimistic and flexibility to become a social needed person with ability. In this process, undergraduate and village officials would exchange their information and communicate each other by various modes with all-around, and form mutual accepted and approved relation. The process includes three phases: anticipatory, encounter and change \& acquisition. By “combination" process, students can obtain a series of proper role behavior as being village officials, develop skill and ability related to working, and adapt university entirely values and general standard by this developing.

\subsection{Anticipatory}

Peasants create material well-being and spiritual wealth simultaneously during the production and construction process in country. Peasants resolve the contradicts and problems as they encounter it while production, through this process then form common awareness and experience, also shape country culture style and custom. These would infiltrate into university culture by unconscious influence and become valuable spiritual wealth while teaching. Country culture will be embodied during the social development as being such universal, its core content is the process of peasants' creating together, accumulation, enjoyment, acknowledge and promotion, it is the result of social historical evolution and all peasants' joint effort.

\subsection{Encounter}

Peasants have already became main supporter for country culture and the foundation of social practice, that is to say, it is peasant who realize the forming structure and enriching to university teaching link. The past experience and values of teaching was no longer in effect when country developing environment changed, external potential crisis cause the vital interests being harmful as students observing culture by firmly entrenched in, it likely consistently promote self-efficiency, hope, optimistic and flexibility etc mentality ability. The successful teaching content replacement needs matching with practice link and this link should include: understanding students' mental motive, the difference of psychological need between country practice and teaching research problem and the importance of continues practice.

\subsection{Change \& Acquisition}

When university teaching evolving process does not conform to country practical developing, the integral management only can be rested on the layer of classroom teaching while it is impossible to go deep into the core values education, the matters of teaching content then belongs to only part of teachers, and that is nothing to do with students' practical ability even cause students to be negative. When student participate it, they would consider their responsibility to social development and be confidence, promote self-efficiency actively, being filled hope to future, keep optimistic mentality and being indomitable to difficulty. It only would be counter-productive if teaching administrator and teachers on the ground impose some kind of theory on students.

\section{The objective analysis for combination of classroom teaching environment and country practical activity}

Combination here means coincidence and inosculation. These years there are more and more researches about combination and its relevance influenced factors, with most of them mainly focus on teaching link and business practical activities. To sum up, there are quite a lot factors that have impact on teaching link and country 
practical activity. It involves students' physiology and psychology factors, direction of running school and quality of teaching factors, social perception and culture factors. Students with various employment backgrounds show the combination with its complex relation between "theory" with "reality" and "culture spirit" with "personality". This paper take the consideration of real sense and self ability, choose ability to organize and coordinate, creation consciousness, social responsibility, self-growth, solving practical issue, adapting society and personality as being correlated variable to discuss the combination target with teaching environment and country practical activity.

\subsection{Ability to organize and coordinate}

In regards to a teaching system, there exists complicated inter-influence among every link in system. There is no constant mode, area and object for country practical activity, in general, students would become active participator under the rather open circumstance and face constantly changing objects. When normal teaching system A1 meets country practical activity A2, it would be certain inter-influence under the condition than these two actions cooperated with each other, and this kind of interaction would affect every elements and the output of whole system.

On this occasion, the combination increment of systematical output is split into two parts, one part is increased output $\Delta 1$ due to synergy effect of $A 2$ on $A 1$, another part is increased output $\Delta 2$ due to synergy effect of $A 1$ on A2. So, $\triangle 1=\mathrm{A} 1 \times \mathrm{A} 2 \quad \triangle 2=\mathrm{A} 2 \times \mathrm{A} 1 \quad \triangle=\triangle 1+\triangle 2=\mathrm{A} 1 \times \mathrm{A} 2+\mathrm{A} 2 \times \mathrm{A} 1$. Therefore, the author assign a topic: the positive impact on synergy effect under the condition that teaching link is tallying with country practical activity.

\subsection{Creation consciousness}

Along with the fattening of university organization hierarchy and the abroad utilizing for crossing function management, the boundary to all fields, roles and hierarchy have became blurring, what mechanism is got by teaching link, in the meantime of realizing oneself and uniqueness of its role, also find that their own role is integrated to larger social culture system or net. So in this case, with no much constraint in classroom and restrict on campus life, the positivity of student is fully transferred, keeps the interest up, thinking also comes alive all-time, more often than not emerge a number of creative sparkle. It is of vital importance to combine teaching link with country practical activity.

Creative consciousness can be considered as key factor to reflex the combination of teaching link and country practical activity. In this paper, the creative consciousness means how belief of personal efficiency play a role in larger social culture system, as appraise students' personal efficiency, it is inevitably to consider those influence that may improve or block the specific motive power during creative process. Therefore, the author assigns a topic: the positive impact on creative consciousness under the condition that teaching link is tallying with country practical activity.

\subsection{Social responsibility}

Most of undergraduates in modern times grow up with book knowledge and with acquaint scarcely to national conditions, conditions of the people, while society is too complex to be comprehended by only reading books, attending several lectures and watching news. Attending country practical activity would open a door to understand. With moving towards to practice and experiencing live, students can get a view of enormous progress of our country and feel the difference between urban and rural, gap of wealth, all of these encourage us to struggle for our motherland's glorious future.

The combination of city culture and rural migrant workers can also affect social responsibility. In this paper, social responsibility means that with the condition of gathering city culture, teaching link and practical activity can be substituted for each other, mutual complemented, mutual accumulated, mutual creative, and can develop continuously with infinity, enhance economic performance to capacity. Therefore, the author assigns a topic: the positive impact on city responsibility under the condition that teaching link is tallying with country practical activity.

\subsection{Self-growth}

By participating country practical activity, students feel their own quality, ability and the gap to social need realistically, catch the sight of their shortage, and this can make them acquaint, appraise themselves with more objectively, adjust their position gradually to society, to mass. Meanwhile, the sense of urgency and crisis emerged make them think self-develop problem with great concentrations, enhance self-quality and ability continually to accommodate social development need.

There are abundant in the ways that country developing brings about benefit to society, which are the factors of 
external cultural environment in country besides personal factors. Single psycho-performance is equal to the combination of individual condition, ability and external social culture context. If teaching link is disjointed to country practical activity, students are unable to bring into play effectively no matter how strong their mental capacity it is. Students can not change country culture environment, if they can not adapt practical activity then they can not accommodate the entire social culture context. Therefore, the author assigns a topic: the positive impact on self-growth under the condition that teaching link is tallying with country practical activity.

\subsection{Solving practical issue}

Undergraduates learn most of time in classroom and the knowledge obtained in class mainly are indirect, systematic theoretical content. Social practice make us get in touch with and step up to society, thus gain abundance of valuable updated knowledge, meanwhile, we could contrast and compare theoretical knowledge to practical phenomenon, gradually translate abstract theoretical knowledge into the ability to solve practical issue.

Ability to solve practical issue can be considered as key factor to reflex the combination of teaching link and country practical activity. In this paper, solving practical issue means teaching link reach social benefit maximizing and strengthens cohesion by all university students' aspiring objective maximizing, form jointly belief and culture for both university and country, and then touch the entire social culture by participating positively. Therefore, the author assigns a topic: the positive impact on solving practical issue under the condition that teaching link is tallying with country practical activity.

\subsection{Adapting society}

With the continuous development in society, the requirement to various kinds' talents changing with it and competition has become essential feature in society. So, person with single knowledge aspect, short of social adapting and lower comprehensive abilities in the dry tree inevitable in market competition, social practice make us engage society widely, to know and constantly participate in social life, to start work, use heart and communicate in practice. It can train and take exercise to our working ability by contacting with all order of society and section directly, and find shortage, improve timely, thus update knowledge structure and gain fresh information to accommodate social need.

Adapting society can be considered as key factor to reflex the combination of teaching link and country practical activity. In this paper, adapting society means that students' social ability is realized by participating in country practical activity, instead of in classroom, students can have sufficient motive power to pursue social goal after graduation, thus, country practical activity would enhance vitality to teaching link. Therefore, the author assigns a topic: the positive impact on adapting society under the condition that teaching link is tallying with country practical activity.

\subsection{Personality}

Undergraduates will come into contact with various people in status in social practice. These groups include activity partner, the masses and teacher. On this occasion, it is particular important of how to work in cooperation with schoolmate, how to coordinate to teacher and the masses, how to handle interpersonal relation correctly and how to get along with others harmonious, while practical activity just can become the condition to test their mastery and moral character. The features of "tender, arrogant" on undergraduates in this generation can be overcome in front of common great masses; it require undergraduates to have certain sacrifice spirit and tough-minded character in face of difficulty and danger.

Personality can be considered as key factor to reflex the combination of teaching link and country practical activity. In this paper, personality means the totaling effect generated by teaching link and country practical activity. Personality is from dynamic process of city and country culture background and it could emerge unhealthy phenomenon without these environment. Therefore, the author assigns a topic: the positive impact on personality under the condition that teaching link is tallying with country practical activity.

\subsection{Propose of study model}

In the above assumes, the author discuss the influence from the combination of teaching link and country practical activity through ability to organize and coordinate, creation consciousness, social responsibility, self-growth, solving practical issue, adapting society and personality seven aspects, and propose corresponding theoretical model on this basis:

\section{Insert Figure 1 here.}

\section{Conclusion}

It can reach the following conclusion according to above analysis: the positive impact on synergy effect under 
the condition that teaching link is tallying with country practical activity;

the positive impact on creative consciousness under the condition that teaching link is tallying with country practical activity; the positive impact on city responsibility under the condition that teaching link is tallying with country practical activity; the positive impact on self-growth under the condition that teaching link is tallying with country practical activity; the positive impact on solving practical issue under the condition that teaching link is tallying with country practical activity; the positive impact on adapting society under the condition that teaching link is tallying with country practical activity; the positive impact on personality under the condition that teaching link is tallying with country practical activity.

\section{References}

Guo, Yuanxiang \& Wu Xiangping. (2003). The idea of composite practical activity course. Beijing.Higher education Press. 139.

Li, Bin. (2006). Village teacher's working in west poor area make people be full of respect. China youth daily, 3.9(6).

Li, Chenzhi. (2003). Exploitation for composite practical activity course. Beijing. People education press. 2.

Li, Yahong, Zhang, Lichang \& Li Fang. (2005). The research for composite practical activity development and teachers' action in operation. Education and scientific research, (6). 8-11.

Liu, Yuexiu, Tan, Renlin \& Xu, Zhengchun. (2005). The practice and exploration for undergraduate tutorial system. Heilongjiang higher education, (8).115.

Lu, Liqiong. (2005). General analysis for American university assistance system and revelation. Fudan education forum, 3(I).62-65.

$\mathrm{Xu}$, Zhengchun, Chen, Ximu \& Chen, Beiguang. Etc. (2004). The study and exploration for developing forestry technological innovation based on tutorial system. China forestry education, (6).

Yao, Qingyan \& Wang, Yuan. (2005). The case of composite practical activity for rural school and its rethink. Education and management, (2).37-39.

Yi, Yang \& Liu, Xiaodong. (2003). Harvard papillary part-time job and meaning. Jiaotong higher education study, (2). 17-21.

Zhao, Liangcheng. (2004). The exploration and practice for higher agriculture \& forestry academy teaching reformation. (5).30-31.

Zhong, Qiquan. Etc. (2001). The reading for base education course reform outline (on trail). Shanghai. ECUN Press. 71.

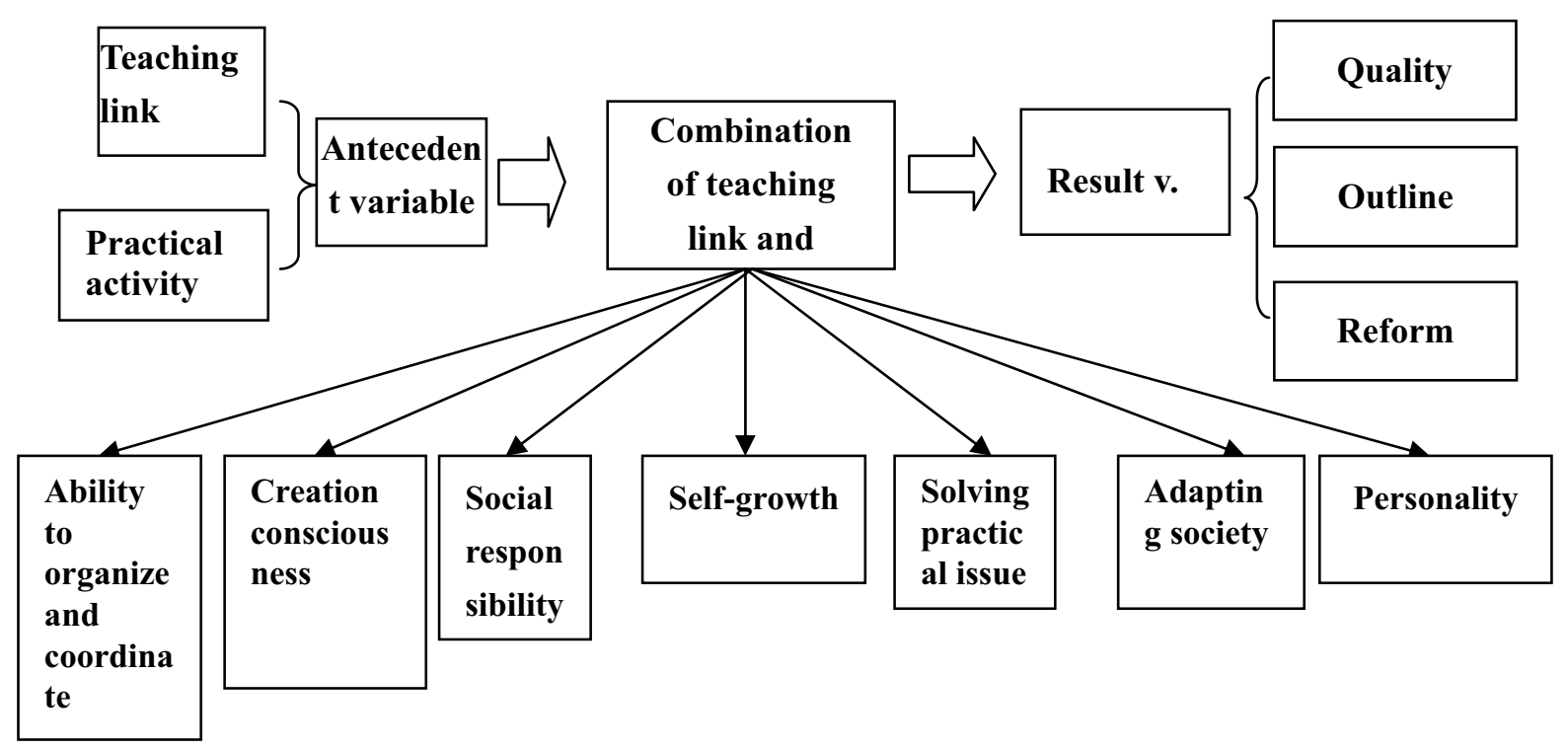

Figure 1. Structure for combination of second order factor 